\title{
Effect of Dietary Phytogenic and Probiotic Supplementation on Productive Performance and Immune Response of Inshas Laying Hens.
}

\author{
Islam, M. El-Sharkawy*1, Mohamed, M. Abdalla ${ }^{2}$, Gaafar, M. El- Gendi ${ }^{3}$, and Ibrahim, M. Assaf ${ }^{4}$ \\ 2, 3 Animal Production Department, Faculty of Agriculture, Benha University, Egypt \\ 1, 4 Animal Production Research Institute, Agriculture Research Center, Giza, Egypt. \\ * Corresponding author: ElSharkawy1919@gmail.com
}

\begin{abstract}
This study was aimed to investigate the effect of dietary supplementation of Pedicoccus acidilactici as probiotic $(\mathrm{P})$, chicory as phytogenic $(\mathrm{C})$ and their interactions between them $(\mathrm{P} \times \mathrm{C})$ on productive performance and immune response of Inshas laying hens. A total number of 720 chickens, 26 weeks old with nearly similar initial average weight were used in this study. Hens were randomly distributed into twelve experimental groups each of 60 birds. A factorial arrangement design $(3 \times 4)$ with three levels of probiotic $(0,0.5$ and $0.1 \mathrm{~g} / \mathrm{kg} \mathrm{diet})$ and four levels of chicory leaves powder $(0,5,10$ and $20 \mathrm{~g} / \mathrm{kg}$ diet $)$ and their interaction were tested for 24 weeks. Results obtained showed highly significant variation $(\mathrm{p}<0.01)$ in averages of feed conversion ratio (FCR), egg production rate (EPR) and egg mass at the most periods of the experiment and all over the experimental period due to all treatments applied, Insignificant variation were found in average body weight, feed intake and egg weight due to dietary levels of probiotic and chicory all over the experimental period, while the interaction between them showed highly significant variation $(\mathrm{p}<0.01)$ in body weight and egg weight only. The best FCR (4.67. 4.64 and $4.03 \mathrm{~g}$ feed/g egg), EPR (53.35, 53.29 and 62.16\% hen/day) and egg mass (26.19, 26.22 and 30.10 $\mathrm{g} /$ hen/day) were found in birds fed diets supplemented with $1.0 \mathrm{~g}$ probiotic, $5 \mathrm{~g}$ chicory $/ \mathrm{kg}$ diet and the interaction between $(\mathrm{P} 2 \times \mathrm{C} 1)$, respectively. Significant improvement $(\mathrm{p}<0.05)$ in immune response toward antibody titers of Newcastle (ND) and Influenza (H9N2) due to dietary probiotic only. The highest values of relative economical efficiency were found $129.20,281.39$ and $270.14 \%$ were listed for diets containing $1.0 \mathrm{~g}$ probiotic, $5 \mathrm{~g}$ chicory $/ \mathrm{Kg}$ diet and their interactions between the same levels, receptively. It could be recommended to use probiotic at a level of $1.0 \mathrm{~g}$, chicory at level of $5 \mathrm{~g} / \mathrm{Kg}$ diet and their interactions $(1.0 \mathrm{~g}$ probiotic $\mathrm{x} 5 \mathrm{~g}$ chicory/ $\mathrm{Kg}$ diet $)$ to improve the productive performance, immune response and economical efficiency of Inshas laying hens.
\end{abstract}

Keyword: laying hens, phytogenic, probiotic, productive and immune response.

\section{Introduction}

Phytogenic feed additives are plant-derived products used in animal feeding in order to improve performance of agricultural livestock. This class of feed additives has recently gained increasing interest, especially for use in poultry, as can be derived from a significant increase in number of scientific publications since 2000 (Windisch et al., 2008). The herbs and plant extracts used as feed additives include many different bio-active ingredients such as alkaloids, bitters, flavonoids, glycosides, mucilage, saponins, tannins phenolics, polyphenols, terpenoids, polypeptide, thymol, cineole, linalool, anethole, allicin, capsaicin, allylisothiocyanate, and piperine (Grashorn, 2010).

Cichorium intybus L., commonly known as chicory, is an erect fairly woody perennial herb, around $1 \mathrm{~m}$ in height with a fleshy taproot of up to 75 $\mathrm{cm}$ in length and large basal leaves and when broken, all plant parts exudates a milky latex (Van Wyk et al., 1997). Cichorium intybus belongs to family asteraceae and widely distributed in Asia and Europe and hardy plant and can endure extreme temperatures during both vegetative and reproductive growth stages (Bais and Ravishankar, 2001). Cichorium intybus is a potentially convenient fiber-rich diet ingredient which improved palatability of diets in broilers and hens. Also, chicory forage has a high content of uronic acids, which in dicotyledonous plants derive from galactosyluronic acid; this acid is the building block in pectin (EMA 2012). Chicory was grown by the ancient Egyptians as a medicinal plant, coffee substitute, and vegetable crop and was occasionally used for animal forage. In the 1970s, it was discovered that the root of chicory contained up to $40 \%$ inulin. This has a linear fructose polymer in which the fructose units are joined by a $\beta(2 \rightarrow 1)$ glycosidic linkage. Inulins are known as prebiotics because they selectively stimulate the growth of beneficial Lactobacillus and Bifidobacterium and have bifidogenic effects (Rehman et al., 2008).

Numerous microorganisms have been considered as probiotics including yeast, fungi, bacteria and mixed cultures comprising of several microbes. In poultry nutrition, probiotic species such as Streptococcus, Lactobacillus, Bifidobacterium, Bacillus, Candida, Saccharomyces and Aspergillus are widely used to avoid poultry diseases and pathogens and improve growth performance of broilers (Awad et al., 2009). Pedicoccus acidilactici is a probiotic bacterium that exhibits positive impacts on the role and the balance of the intestinal flora; also it reinforces the immune defense and improves the animal and poultry performance (Quarantelli et $\boldsymbol{a l}$., 2008). 
The aim of this study was to evaluate the effect of dietary supplementation of probiotics, chicory and their interaction between them as feed additives on productive performance and immune response of Inshas laying hens.

\section{Materials and methods}

The experimental work of the present study was carried out at Inshas poultry Research Station, Animal Production Research Institute, Agriculture Research Center, Giza, Egypt, from 8September 2017 to 8 March 2018. Bio-chemical analysis was performed at the laboratories of Animal Production Research Institute, Ministry of agriculture.
A total number of seven hundred and twenty laying hens of Inshas Local strain, 26 weeks old, were randomly chosen from a large commercial flock. All selected hens and cocks were approximately of an equal body weight and similar performance. Birds were legs banded, housed in floor pens in a density of 5 hens/square meter. All birds were reared under the same managerial and hygienic condition and fed a basal laying ration formulated according to recommendations of NRC (1994). Feed ingredients and chemical analysis of the basal laying ration are shown in Table (1). The photoperiod during three experimental periods was fixed at 16 hour daily.

Table 1. Feed ingredients and chemical analysis of the basal laying ration.

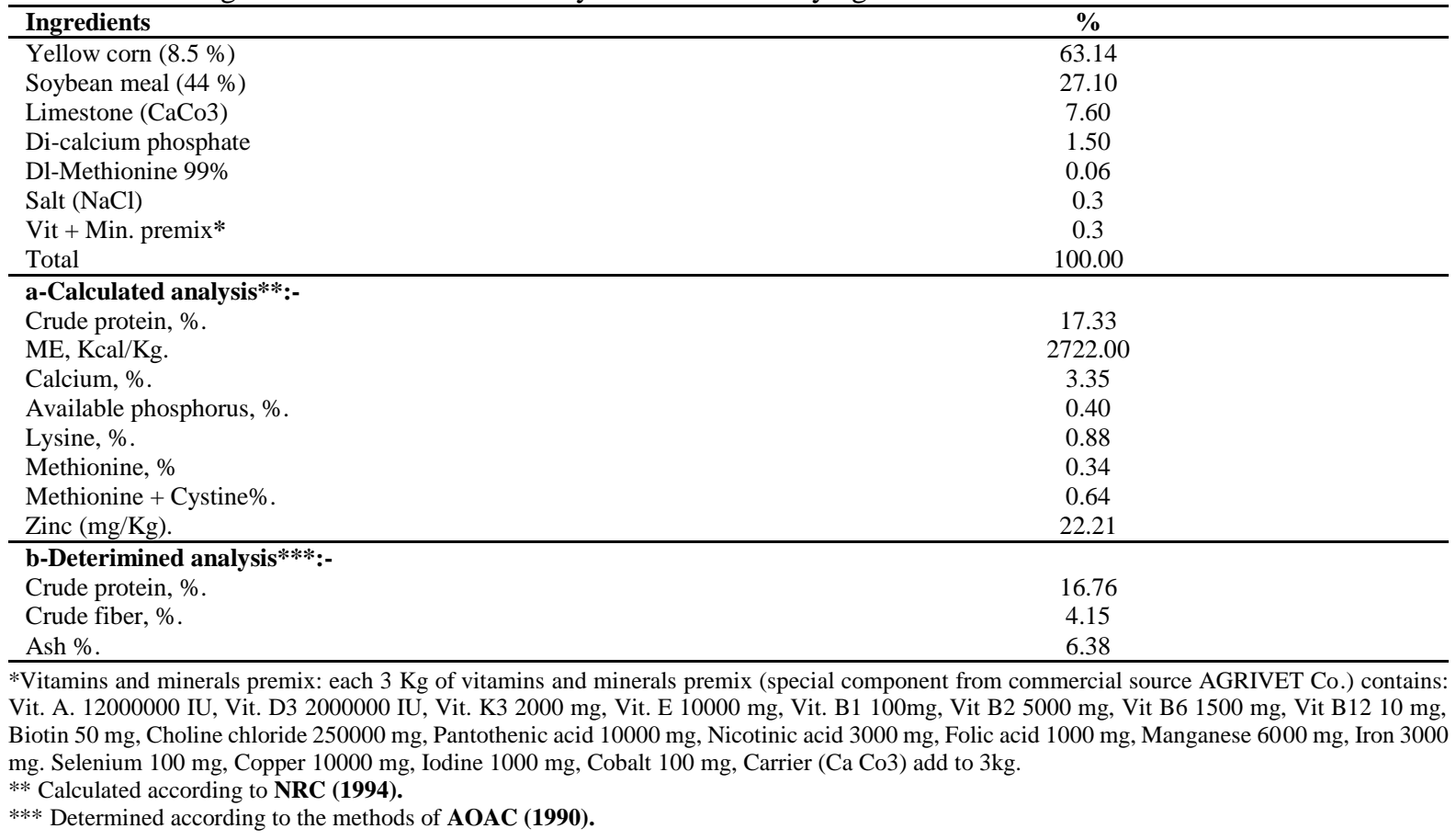

\section{Grouping birds and experimental design:}

Experimental birds were divided into twelve groups each of 60 hens. Each group was re-divided into three replicates each of 20 hens. A (3x4) factorial experimental design with three levels of Pedicoccus acidilacticias as probiotics $(0,0.5$ and $0.1 \mathrm{~g} / \mathrm{kg}$ diet $)$ and four levels of chicory as phytogenics $(0,5,10$ and $20 \mathrm{~g} / \mathrm{kg}$ diet) and their interaction were tested for 24 weeks.

\section{Data collection and estimated traits.}

Birds of each experimental group were individually weighed to the nearest $g$ at the beginning of the experiment to determine the initial live body weight and then at 34, 42 and 50 weeks of age (the end of the experimental period). Feed intake (FI) by all birds of each experimental group was weekly recorded, it was then averaged and expressed in grams per bird per day during the periods from 26-33, 34-42 and 43-50 weeks of birds age and all over the experimental period. Feed conversion ratio (FCR) was then calculated for each experimental period according to the following formula:

FCR $=$ Feed intake $(\mathrm{g}) /$ Egg mass $(\mathrm{g})$

Traits of egg production.

Egg production rate, egg weight and egg mass.

Numbers of eggs were daily and individually recorded for hens within each experimental group. Egg production average was then calculated every eight weeks for each group. The egg production rate was calculated as follows:

Egg production rate $(\%)=$ $\frac{\text { Number of eggs produced }}{\text { Number of live hens }} \times 100$

Eggs laid by hens of each experimental group were individually weighed daily to the nearest gram during 
the experimental periods. Then average egg weight per hens for each experimental group was calculated every eight weeks. Egg mass was obtained by multiplying the total number of eggs laid by the average egg weight for each experimental group. Egg mass was calculated every eight weeks per hens of each experimental group.

\section{Humoral immune response:}

At 50 weeks of age heparinized blood samples were randomly taken from 5 birds from each treatment, blood samples were collected and centrifuged at $3500 \mathrm{rpm}$ for 15 minutes. Separated Plasma produced was transferred and stored in the deep freezer at approximately $-20^{\circ} \mathrm{C}$ till the time of the antibody titer of Newcastle disease virus (NDV) and A vain influenza (H9N2) was detected by the hemagglutination inhibition methods (HI) assays according to the OIE standard protocol using haemagglutination (HA) units of homologous antigen(NDV and H9 virus) OIE (2008).

\section{Statistical Analysis:}

Data were statically analyzed according to ANOVA procedures of SAS (SAS 2004). Mean differences were compared using Duncan's multiple range test (Duncan, 1955) and the following model was used:

$$
X_{i j k}=\mu+A_{i}+B_{j}+(A B)_{i j}+e_{i j k} .
$$

Whereas:

$\mathbf{X}_{\mathbf{i j k}}=$ Number of observations. $\quad \boldsymbol{\mu}=$ the overall means of the respective variables.

$\mathbf{A}_{\mathbf{i}}=$ the effect of probiotic. $\quad \mathbf{B}_{\mathbf{j}}=$ the effect of phyotogenic.

$(A B)_{i j}=$ the interaction between probiotic and photogenic. $\mathbf{e}_{\mathbf{i j k}}=$ Residual error.

\section{Results and discussions}

\section{Live body weight (LBW).}

The results obtained in table (2) showed significant effect $(\mathrm{P}<0.05)$ on average LBW on laying hens at 42 weeks of bird's age only due to feeding on diets with probiotic levels supplementation. Hens fed the diet with probiotic at the level of $0.5 \mathrm{~g} / \mathrm{Kg}$ diet had the highest average of $\mathrm{LBW}$, then by those fed $1.0 \mathrm{~g}$ probiotic $/ \mathrm{Kg}$ diet compared with the control group. The improvement in LBW may be due to the increased efficiency of digestion and nutrient absorption processes due to presence of the probiotic bacteria (Alkhalf $\boldsymbol{e t}$ al., 2010a).

Table 2. Least square means and standard error $\left(\mathrm{X}^{-} \pm\right.$S.E. $)$for body weight of birds of different experimental groups as affected by dietary supplementation.

\begin{tabular}{|c|c|c|c|c|c|c|}
\hline \multicolumn{2}{|c|}{ Variables } & \multicolumn{5}{|c|}{ Body weight (g) at weeks } \\
\hline Treatments & $\begin{array}{c}\text { Levels } \\
\text { (g/kg diet) }\end{array}$ & 26 & 34 & 42 & 50 & $\begin{array}{c}\text { Average } \\
(26-50)\end{array}$ \\
\hline \multirow{4}{*}{$\begin{array}{l}\text { Probiotic } \\
\text { (P) }\end{array}$} & $\mathrm{P} 0=$ control & $1352.92 \pm 18.58$ & $1447.71 \pm 18.92$ & $1486.8 \pm 15.51^{\mathrm{b}}$ & $1599.5 \pm 20.98$ & $1471.73 \pm 10.84$ \\
\hline & $\mathrm{P} 1=0.5$ & $1355.84 \pm 16.92$ & $1466.67 \pm 15.31$ & $1547.3 \pm 14.59^{\mathrm{a}}$ & $1629.61 \pm 19.25$ & $1497.91 \pm 9.26$ \\
\hline & $\mathrm{P} 2=1.0$ & $1398.34 \pm 19.08$ & $1472.63 \pm 17.82$ & $1502.09 \pm 18.65^{\mathrm{b}}$ & $1595.66 \pm 17.78$ & $1490.83 \pm 11.91$ \\
\hline & & NS & NS & $*$ & NS & NS \\
\hline \multirow{5}{*}{$\begin{array}{l}\text { Chicory } \\
\text { (C) }\end{array}$} & $\mathrm{C} 0=$ control & $1368.89 \pm 20.04$ & $1484.06 \pm 24.19$ & $1519.28 \pm 16.63$ & $1580 \pm 24.74$ & $1486.16 \pm 13.74$ \\
\hline & $\mathrm{C} 1=5$ & $1370.00 \pm 25.53$ & $1464.45 \pm 17.68$ & $1490.56 \pm 17.87$ & $1612.95 \pm 23.93$ & $1482.46 \pm 14.83$ \\
\hline & $\mathrm{C} 2=10$ & $1372.78 \pm 20.66$ & $1447.23 \pm 18.63$ & $1500.62 \pm 20.85$ & $1601.67 \pm 17.91$ & $1480.57 \pm 8.86$ \\
\hline & $\mathrm{C} 3=20$ & $1364.45 \pm 20.38$ & $1453.62 \pm 19.42$ & $1537.78 \pm 22.21$ & $1636.62 \pm 22.36$ & $1498.12 \pm 12.38$ \\
\hline & & NS & NS & NS & NS & NS \\
\hline \multirow{13}{*}{$\begin{array}{l}\text { Interactions } \\
\quad(\mathrm{P} X \mathrm{C})\end{array}$} & $\mathrm{P} 0 \mathrm{X} \mathrm{C} 0$ & $1350.00 \pm 21.76$ & $1398.34 \pm 40.04^{b}$ & $1485.00 \pm 31.28$ & $1506.34 \pm 43.48^{c}$ & $1434.92 \pm 19.69^{\mathrm{e}}$ \\
\hline & P0 X C1 & $1345.00 \pm 50.52$ & $1496.67 \pm 22.17^{\mathrm{ab}}$ & $1500.00 \pm 28.99$ & $1628.34 \pm 31.23^{\mathrm{ab}}$ & $1492.50 \pm 20.15^{\text {abcde }}$ \\
\hline & $\mathrm{P} 0 \mathrm{X} \mathrm{C} 2$ & $1378.34 \pm 41.59$ & $\underset{\mathrm{ab}}{1465.00 \pm 34.53}$ & $1507.17 \pm 36.73$ & $1639.67 \pm 37.82^{a b}$ & $1497.55 \pm 14.00^{\text {abcde }}$ \\
\hline & P0 X C3 & $1338.34 \pm 37.55$ & $1430.84 \pm 47.06^{b}$ & $1455.00 \pm 30.64$ & $1623.67 \pm 38.21^{\mathrm{abc}}$ & $1461.96 \pm 25.71^{\text {abcde }}$ \\
\hline & P1 X C0 & $1336.67 \pm 39.39$ & $\begin{array}{c}1498.34 \pm 26.26 \\
\text { ab }\end{array}$ & $1532.84 \pm 29.17$ & $1579.80 \pm 39.22^{\mathrm{abc}}$ & $1481.23 \pm 16.45^{\text {abcde }}$ \\
\hline & P1 X C1 & $1338.34 \pm 23.45$ & $\underset{\mathrm{ab}}{1483.34 \pm 35.47}$ & $1511.67 \pm 33.51$ & $1670.34 \pm 41.06^{\mathrm{a}}$ & $1500.92 \pm 25.70^{\text {abcd }}$ \\
\hline & $\mathrm{P} 1 \mathrm{X}$ C2 & $1401.67 \pm 37.99$ & $1430.00 \pm 29.22^{b}$ & $1553.00 \pm 24.49$ & $1597.84 \pm 26.81^{\mathrm{abc}}$ & $1495.63 \pm 14.46^{\text {abcde }}$ \\
\hline & P1 X C3 & $1346.67 \pm 33.93$ & $\underset{\mathrm{ab}}{1455.00 \pm 30.96}$ & $1591.67 \pm 25.36$ & $1662.17 \pm 41.53^{\mathrm{a}}$ & $1513.88 \pm 18.11^{a b c}$ \\
\hline & $\mathrm{P} 2 \mathrm{X} \mathrm{C0}$ & $1420.00 \pm 35.60$ & $1555.50 \pm 33.81^{\mathrm{a}}$ & $1540.00 \pm 25.17$ & $1653.84 \pm 24.07^{\mathrm{a}}$ & $1542.34 \pm 10.20^{\mathrm{a}}$ \\
\hline & $\mathrm{P} 2 \mathrm{X} \mathrm{C} 1$ & $1426.67 \pm 50.78$ & $1413.34 \pm 25.26^{b}$ & $1460.00 \pm 31.63$ & $1525.60 \pm 32.73^{a b c}$ & $1453.95 \pm 30.43^{\text {cde }}$ \\
\hline & P2 X C2 & $1338.34 \pm 27.74$ & $1446.67 \pm 37.03^{b}$ & $1441.67 \pm 35.07$ & $1567.50 \pm 24.39^{\mathrm{abc}}$ & $1448.55 \pm 9.29^{\mathrm{de}}$ \\
\hline & P2 X C3 & $1408.34 \pm 33.01$ & $\begin{array}{c}1475.00 \pm 21.88 \\
\mathrm{ab}\end{array}$ & $1566.67 \pm 36.49$ & $1624.00 \pm 41.43^{\mathrm{abc}}$ & $1518.5 \pm 13.37^{a b}$ \\
\hline & & NS & $*$ & NS & $* *$ & $* *$ \\
\hline
\end{tabular}

$\mathrm{a}$ and $\mathrm{b}$ means with different superscripts within the same column are significantly different. $*=(\mathrm{P}<0.05)$ and $* *=(\mathrm{P}<0.01)$.

These results agreed with those reported by Lalev et al., (2011) who founded that supplemented of with $0.5 \mathrm{~g} / \mathrm{Kg}$ diet had the higher LBW compared with the control group, then by hens fed $1.0 \mathrm{~g}$ probiotic $/ \mathrm{Kg}$ diet were a positive effect on LBW of breeder hens of line $\mathrm{K}$ - White Plymouth rock.

Insignificant variations were found in average LBW due to the levels of chicory dietary 
supplementation at all experimental periods. The results obtained agreed with the findings of Lin et al., (2014) who reported that using different levels of chicory inulin water solution by intragastric administration $(5,10,20 \mathrm{~g} / \mathrm{kg}$ diet $)$ there was no significant difference in body weight among all groups during the experimental period.

Interaction between probiotic and chicory levels of dietary supplementation showed significant effect $(\mathrm{P}$ $<0.05)$ on LBW at 34 weeks and was high significant $(\mathrm{P}<0.01)$ at 50 weeks and all over the experimental period. These results indicate that the phytogenic product under investigation and probiotics have a growth promoting effect on hens. The higher LBW averages were found in the interactions between $(\mathbf{P 2}$ $\mathbf{X ~ C 0 )}$ and (P2 X C3). These results are in agreement with those reported by Perićet al., (2010) who showed that a significant positive effect of probiotic and phytogenic treatments on body weight of broilers.

\section{Feed intake (FI)}

Significant variations $(\mathrm{P}<0.05)$ were found in FI due to feeding diets supplemented with different levels of probiotics during the periods from (26-34) and (42-50) weeks compared with others periods (Table, 3). The higher daily FI was observed in hens fed diet with probiotics at a level of $1.0 \mathrm{~g} / \mathrm{Kg}$ diet. Increasing FI of probiotics supplementation may be due to an increase in digestion, absorption, and availability of nutrition, positively effecting intestine activity, and increasing digestive enzyme Edens (2003) and Hatab et al., (2016). Highly significant variations $(P<0.05)$ were found in average FI due dietary chicory supplementation at (42-50) weeks of bird's age only (Table, 3 ). This may be due to the prebiotic effects of chicory forage or its extracts (such as inulin and oligofructose) on chicken's health which have been reported previously (Mansoub, 2011).

Interaction between probiotic and chicory levels of dietary supplementation had significant effect $(\mathrm{P}<$ $0.05)$ on FI at (42-50) weeks only. The higher FI averages were found in the interactions between $(\mathbf{P 0}$ $\mathbf{X ~ C 0 ) . ~ T h e ~ r e s u l t s ~ o b t a i n e d ~ d i s a g r e e ~ w i t h ~ t h o s e ~ o f ~}$ Taraz et al., (2015) who recorded that there were no significant differences in feed intake of broilers treated with Chicory extract levels and probiotics compared with control.

Table 3. Least square means and standard error $\left(\mathrm{X}^{-} \pm\right.$S.E. $)$for feed intake of birds of different experimental groups as affected by dietary supplementation.

\begin{tabular}{|c|c|c|c|c|c|}
\hline \multicolumn{2}{|c|}{ Variables } & \multicolumn{4}{|c|}{ Feed intake (g/bird/day) at weeks } \\
\hline Treatments & $\begin{array}{c}\text { Levels } \\
\text { (g/kg diet) }\end{array}$ & 26-34 & $34-42$ & $42-50$ & $\begin{array}{c}\text { Average } \\
(26-50)\end{array}$ \\
\hline \multirow{3}{*}{$\begin{array}{l}\text { Probiotic } \\
\text { (P) }\end{array}$} & $\mathrm{P} 0=$ control & $119.6 \pm 0.39^{b}$ & $120.55 \pm 0.47$ & $121.18 \pm 0.41^{\mathrm{a}}$ & $120.44 \pm 0.29$ \\
\hline & $\mathrm{P} 1=0.5$ & $120.95 \pm 0.28^{a}$ & $117.13 \pm 1.64$ & $119.69 \pm 0.56^{\mathrm{b}}$ & $119.26 \pm 0.65$ \\
\hline & $\mathrm{P} 2=1.0$ & $\begin{array}{c}121.49 \pm 0.29^{\mathrm{a}} \\
* *\end{array}$ & $\begin{array}{c}119.19 \pm 1.33 \\
\text { NS }\end{array}$ & $\begin{array}{c}120.37 \pm 0.2^{\mathrm{ab}} \\
*\end{array}$ & $\begin{array}{c}120.35 \pm 0.48 \\
\text { NS }\end{array}$ \\
\hline \multirow{4}{*}{$\begin{array}{l}\text { Chicory } \\
\text { (C) }\end{array}$} & $\mathrm{C} 0=$ control & $121.02 \pm 0.63$ & $119.76 \pm 0.37$ & $121.51 \pm 0.36^{\mathrm{a}}$ & $120.76 \pm 0.18$ \\
\hline & $\mathrm{C} 1=5$ & $120.68 \pm 0.37$ & $119.74 \pm 1.54$ & $120.47 \pm 0.22^{a b}$ & $120.30 \pm 0.53$ \\
\hline & $\mathrm{C} 2=10$ & $120.75 \pm 0.21$ & $116.26 \pm 1.93$ & $119.50 \pm 0.48^{b}$ & $118.84 \pm 0.66$ \\
\hline & $\mathrm{C} 3=20$ & $120.26 \pm 0.42$ & $120.06 \pm 2.04$ & $120.18 \pm 0.81^{b}$ & $120.17 \pm 0.89$ \\
\hline \multirow{14}{*}{$\begin{array}{l}\text { Interactions } \\
(\mathrm{P} \times \mathrm{C})\end{array}$} & & NS & NS & $* *$ & NS \\
\hline & P0 X C0 & $119.68 \pm 1.10$ & $122.18 \pm 0.65$ & $122.37 \pm 0.13^{a b}$ & $121.41 \pm 0.54$ \\
\hline & P0 X C1 & $118.82 \pm 0.37$ & $120.64 \pm 0.45$ & $122.54 \pm 0.08^{a}$ & $120.67 \pm 0.01$ \\
\hline & P0 X C2 & $119.85 \pm 1.09$ & $119.2 \pm 0.60$ & $120.09 \pm 0.43^{\mathrm{cd}}$ & $119.71 \pm 0.42$ \\
\hline & P0 X C3 & $120.05 \pm 0.62$ & $120.17 \pm 1.23$ & $119.70 \pm 0.14^{\mathrm{cd}}$ & $119.97 \pm 0.66$ \\
\hline & $\mathrm{P} 1 \mathrm{X} \mathrm{C0}$ & $121.63 \pm 0.08$ & $116.7 \pm 5.18$ & $121.14 \pm 0.38^{\mathrm{abc}}$ & $119.83 \pm 1.76$ \\
\hline & P1 X C1 & $120.56 \pm 0.20$ & $118.28 \pm 0.48$ & $118.68 \pm 0.23^{\mathrm{d}}$ & $119.17 \pm 0.17$ \\
\hline & $\mathrm{P} 1 \mathrm{X} \mathrm{C} 2$ & $121.18 \pm 0.70$ & $114.65 \pm 5.09$ & $118.48 \pm 1.67^{\mathrm{d}}$ & $118.11 \pm 2.23$ \\
\hline & $\mathrm{P} 1 \mathrm{X} \mathrm{C} 3$ & $120.43 \pm 0.81$ & $118.87 \pm 0.78$ & $120.47 \pm 1.06^{\mathrm{bcd}}$ & $119.92 \pm 0.35$ \\
\hline & $\mathrm{P} 2 \times \mathrm{C} 0$ & $121.76 \pm 0.48$ & $120.41 \pm 0.19$ & $121.01 \pm 0.04^{\mathrm{abc}}$ & $121.06 \pm 0.21$ \\
\hline & $\mathrm{P} 2 \mathrm{X} \mathrm{C} 1$ & $122.65 \pm 0.24$ & $120.30 \pm 0.67$ & $120.18 \pm 0.37^{\mathrm{cd}}$ & $121.04 \pm 0.18$ \\
\hline & $\mathrm{P} 2 \times \mathrm{C} 2$ & $121.24 \pm 0.14$ & $114.92 \pm 5.01$ & $119.93 \pm 0.60^{\mathrm{cd}}$ & $118.69 \pm 1.68$ \\
\hline & $\mathrm{P} 2 \mathrm{X} \mathrm{C} 3$ & $120.30 \pm 0.29$ & $121.15 \pm 0.85$ & $120.38 \pm 0.23^{\mathrm{bcd}}$ & $120.61 \pm 0.46$ \\
\hline & & NS & NS & $*$ & NS \\
\hline
\end{tabular}

\section{Feed conversion ratio (FCR).}

Significant variations $(\mathrm{P}<0.05)$ were found in FCR due to feeding diets supplemented with different levels of probiotic at all periods of estimation except at the period from (42-50) weeks (Table, 4). The best feed conversion values were observed in hens fed diets supplemented with probiotic at a level of 1.0 $\mathrm{g} / \mathrm{Kg}$ diet when compared with control group. This improvement in FCR by additional probiotic could be related to its promoting effects on metabolism of digestion processes and utilization of nutrients (Khanet al., 2011). These results were agreed with those stated by Alkhalf et al., (2010a) and Mikulski et al., (2012) they reported that supplementation $1 \mathrm{~g}$ $/ \mathrm{kg}$ feed of the probiotic (Pediococcus acidilactici) to chickens diet improve FCR.

Highly significant variations $(\mathrm{P}<0.01)$ on FCR were found due dietary chicory supplementation at all 
periods of estimation. The best feed conversion values were observed in hens fed diets supplemented with chicory at a level of 5,20 and $10 \mathrm{~g} / \mathrm{Kg}$ diet, respectively at all experimental period when compared with control group. The improvement of FCR due to dietary chicory supplementation may be attributed to stimulate the production of secretions in the small intestinal mucosa, pancreas and liver, which leads to help digestion. These results agreed with those stated by Nobakht (2015) they showed that use different levels (Cichorium intybus L) had significant improvement on FCR of Hy-line laying hens (from 52 to 63 weeks of age).

The interaction effect between dietary probiotic and chicory levels had highly significant effect $(\mathrm{P}<0.01)$ on FCR at all experimental periods except at period from (42-50) weeks. The best FCR averages were found in the interactions between (P2 X C1) and (P2 X C2). These results were agreed with those stated by Taraz et al., (2015) who indicated that inclusion chicory extract and probiotic improved FCR.

Table 4. Least square means and standard error $\left(\mathrm{X}^{-} \pm\right.$S.E. $)$for feed conversion ratio of birds of different experimental groups as affected by dietary supplementation.

\begin{tabular}{|c|c|c|c|c|c|}
\hline \multicolumn{2}{|c|}{ Variables } & \multicolumn{4}{|c|}{ Feed conversion ratio (g feed/g egg) at weeks } \\
\hline Treatments & $\begin{array}{c}\text { Levels } \\
\text { (g/kg diet) }\end{array}$ & 26-34 & 34-42 & $42-50$ & $\begin{array}{c}\text { Average } \\
(26-50) \\
\end{array}$ \\
\hline \multirow{3}{*}{$\begin{array}{l}\text { Probiotic } \\
\text { (P) }\end{array}$} & $\mathrm{P} 0=$ control & $4.29 \pm 0.14^{\mathrm{a}}$ & $5.26 \pm 0.12^{\mathrm{a}}$ & $5.73 \pm 0.14$ & $4.99 \pm 0.10^{\mathrm{a}}$ \\
\hline & $\mathrm{P} 1=0.5$ & $4.53 \pm 0.18^{\mathrm{a}}$ & $5.20 \pm 0.25^{\mathrm{a}}$ & $5.66 \pm 0.21$ & $5.06 \pm 0.20^{\mathrm{a}}$ \\
\hline & $\mathrm{P} 2=1.0$ & $\begin{array}{c}4.02 \pm 0.11^{\mathrm{b}} \\
* *\end{array}$ & $\begin{array}{c}4.81 \pm 0.26^{b} \\
*\end{array}$ & $\begin{array}{c}5.55 \pm 0.32 \\
\mathrm{NS}\end{array}$ & $\begin{array}{c}4.67 \pm 0.19^{b} \\
*\end{array}$ \\
\hline \multirow{4}{*}{$\begin{array}{l}\text { Chicory } \\
\text { (C) }\end{array}$} & $\mathrm{C} 0=$ control & $4.79 \pm 0.18^{\mathrm{a}}$ & $5.74 \pm 0.30^{\mathrm{a}}$ & $6.63 \pm 0.38^{a}$ & $5.58 \pm 0.23^{\mathrm{a}}$ \\
\hline & $\mathrm{C} 1=5$ & $4.18 \pm 0.10^{b}$ & $4.84 \pm 0.18^{b}$ & $5.09 \pm 0.11^{b}$ & $4.64 \pm 0.10^{\mathrm{b}}$ \\
\hline & $\mathrm{C} 2=10$ & $4.13 \pm 0.13^{b}$ & $4.88 \pm 0.29^{b}$ & $5.56 \pm 0.28^{b}$ & $4.76 \pm 0.22^{b}$ \\
\hline & $\mathrm{C} 3=20$ & $\begin{array}{c}4.02 \pm 0.19^{\mathrm{b}} \\
* *\end{array}$ & $\begin{array}{c}4.91 \pm 0.23^{b} \\
* *\end{array}$ & $\begin{array}{c}5.31 \pm 0.14^{\mathrm{b}} \\
* *\end{array}$ & $\begin{array}{c}4.66 \pm 0.18^{b} \\
* *\end{array}$ \\
\hline \multirow{12}{*}{$\begin{array}{l}\text { Interactions } \\
\text { (P X C) }\end{array}$} & $\mathrm{PO}$ X C0 & $4.75 \pm 0.41^{\mathrm{ab}}$ & $5.06 \pm 0.19^{\mathrm{bcde}}$ & $6.32 \pm 0.10$ & $5.27 \pm 0.27^{b c}$ \\
\hline & P0 X C1 & $4.32 \pm 0.03^{\mathrm{bcd}}$ & $5.70 \pm 0.06^{\mathrm{abc}}$ & $5.32 \pm 0.08$ & $5.04 \pm 0.01^{b c d}$ \\
\hline & P0 X C2 & $3.85 \pm 0.09 \mathrm{def}$ & $5.04 \pm 0.32^{\text {bcde }}$ & $5.61 \pm 0.29$ & $4.69 \pm 0.20^{\mathrm{cde}}$ \\
\hline & P0 X C3 & $4.24 \pm 0.08^{\text {bcde }}$ & $5.27 \pm 0.14^{b c}$ & $5.68 \pm 0.22$ & $4.96 \pm 0.03^{\mathrm{bcd}}$ \\
\hline & P1 X C0 & $5.23 \pm 0.07^{\mathrm{a}}$ & $6.38 \pm 0.11^{\mathrm{a}}$ & $6.65 \pm 0.2$ & $5.99 \pm 0.06^{\mathrm{a}}$ \\
\hline & P1 X C1 & $4.57 \pm 0.04^{b c}$ & $4.86 \pm 0.11^{\mathrm{cde}}$ & $5.24 \pm 0.2$ & $4.86 \pm 0.11^{\mathrm{cde}}$ \\
\hline & P1 X C2 & $4.62 \pm 0.21^{b c}$ & $5.23 \pm 0.42^{\text {bcd }}$ & $5.72 \pm 0.1$ & $5.13 \pm 0.23^{b c}$ \\
\hline & P1 X C3 & $3.70 \pm 0.09$ ef & $4.34 \pm 0.07$ ef & $5.01 \pm 0.11$ & $4.27 \pm 0.02$ ef \\
\hline & P2 X C0 & $4.40 \pm 0.12^{\mathrm{bcd}}$ & $5.77 \pm 0.59^{a b}$ & $6.90 \pm 0.88$ & $5.46 \pm 0.42^{\mathrm{ab}}$ \\
\hline & P2 X C1 & $3.64 \pm 0.11^{\mathrm{f}}$ & $3.97 \pm 0.13^{\mathrm{f}}$ & $4.70 \pm 0.18$ & $4.03 \pm 0.05^{f}$ \\
\hline & $\mathrm{P} 2 \mathrm{X} \mathrm{C} 2$ & $3.90 \pm 0.17$ ef & $4.37 \pm 0.21^{\operatorname{def}}$ & $5.36 \pm 0.01$ & $4.46 \pm 0.12^{\mathrm{def}}$ \\
\hline & P2 X C3 & $\begin{array}{c}4.12 \pm 0.24^{\text {cdef }} \\
* *\end{array}$ & $\begin{array}{c}5.06 \pm 0.19 \text { bcde } \\
* *\end{array}$ & $\begin{array}{l}5.25 \pm 0.01 \\
\text { NS }\end{array}$ & $\begin{array}{c}4.75 \pm 0.21^{\mathrm{cde}} \\
* *\end{array}$ \\
\hline
\end{tabular}

a, b, c, d, e and f means with different superscripts within the same column are significantly different. $*=(\mathrm{P}<0.05)$ and $* *=(\mathrm{P}<0.01)$.

\section{Egg production rate (EPR).}

Data presented in table (5) showed that hens fed diet supplemented with probiotic had highly significant affect $(\mathrm{P}<0.01)$ EPR at all experimental periods except at the period from (42-50) weeks. The higher EPR was observed in hens fed diets supplemented with probiotic at a level of $1.0 \mathrm{~g} / \mathrm{kg} \mathrm{diet}$ (53.35) compared with control group (49.26 $\% /$ hen/day). The mechanism explained that the increased EPR by probiotic might be due to the elongated shape of small and large intestine as well as their suppressing effects on pathogen bacteria and stimulating effects on the growth and activity of beneficial bacteria probiotic in the intestines which increase absorption of nutrient (Chen et al., 2005). These results are in close agreement with those obtained by Quarantelli et $\boldsymbol{a l}$., (2008) reported that the addition of Bactocell@ (Pediococcus acidilactici) at the dose of $109 \mathrm{UFC} / \mathrm{kg}$ of feed were improved the EPR $(+2.39 \%)$ of Hy-line laying hens.

Dietary supplementation of chicory and the interaction between chicory and probiotic had highly significant effect $(\mathrm{P}<0.01)$ on average EPR at all periods of estimation. The higher EPR was observed in hens fed diets supplemented with chicory at a level of 5 and $20 \mathrm{~g} / \mathrm{Kg}$ diet and interaction between (P2 X $\mathrm{C} 1)$ and (P1 X C3), respectively when compared with the control group and other interactions applied. The results obtained agree with those obtained by Mansoub (2011) who showed that using plant chicory powder (Cichorium intybus L.) with different dietary level had significant effects $(\mathrm{P}<0.05)$ on egg production rate of Hy- line hens and the higher EPR by levels. 
Table 5. Least square means and standard error $\left(X^{-} \pm\right.$S.E. $)$for egg production rate of birds of different experimental groups as affected by dietary supplementation.

\begin{tabular}{|c|c|c|c|c|c|}
\hline \multicolumn{2}{|c|}{ Variables } & \multicolumn{4}{|c|}{ Egg production rate $(\% /$ hen/day $)$ at weeks } \\
\hline Treatments & $\begin{array}{c}\text { Levels } \\
\text { (g/kg diet) }\end{array}$ & 26-34 & 34-42 & $42-50$ & $\begin{array}{c}\text { Average } \\
(26-50)\end{array}$ \\
\hline \multirow{4}{*}{$\begin{array}{l}\text { Probiotic } \\
\text { (P) }\end{array}$} & $\mathrm{P} 0=$ control & $59.17 \pm 1.61^{b}$ & $46.32 \pm 1.01^{b}$ & $42.30 \pm 0.93$ & $49.26 \pm 0.79^{b}$ \\
\hline & $\mathrm{P} 1=0.5$ & $56.61 \pm 2.30^{\mathrm{b}}$ & $46.06 \pm 2.24^{\mathrm{b}}$ & $42.44 \pm 1.38$ & $48.37 \pm 1.92^{b}$ \\
\hline & $\mathrm{P} 2=1.0$ & $64.23 \pm 2.10^{\mathrm{a}}$ & $51.18 \pm 2.39^{\mathrm{a}}$ & $44.66 \pm 1.95$ & $53.35 \pm 2.03^{\mathrm{a}}$ \\
\hline & & $* *$ & $* *$ & NS & $* *$ \\
\hline \multirow{5}{*}{$\begin{array}{l}\text { Chicory } \\
\text { (C) }\end{array}$} & $\mathrm{C} 0=$ control & $53.36 \pm 2.99^{b}$ & $42.4 \pm 2.95^{b}$ & $37.02 \pm 2.38^{\mathrm{c}}$ & $44.26 \pm 2.55^{b}$ \\
\hline & $\mathrm{C} 1=5$ & $61.84 \pm 1.26^{\mathrm{a}}$ & $50.84 \pm 1.30^{\mathrm{a}}$ & $47.19 \pm 0.93^{\mathrm{a}}$ & $53.29 \pm 0.90^{\mathrm{a}}$ \\
\hline & $\mathrm{C} 2=10$ & $61.26 \pm 1.36^{\mathrm{a}}$ & $48.54 \pm 2.43^{\mathrm{a}}$ & $42.98 \pm 1.71^{\mathrm{b}}$ & $50.93 \pm 1.80^{\mathrm{a}}$ \\
\hline & $\mathrm{C} 3=20$ & $63.55 \pm 2.72^{\mathrm{a}}$ & $49.63 \pm 2.24^{\mathrm{a}}$ & $45.34 \pm 1.19^{a b}$ & $52.84 \pm 2.02^{\mathrm{a}}$ \\
\hline & & $* *$ & $* *$ & $* *$ & $* *$ \\
\hline \multirow{12}{*}{$\begin{array}{l}\text { Interactions } \\
\quad(\mathrm{P} \text { X C) }\end{array}$} & $\mathrm{P} 0 \mathrm{X} \mathrm{C0}$ & $54.85 \pm 4.85^{\mathrm{e}}$ & $49.29 \pm 1.72^{\mathrm{cd}}$ & $39.13 \pm 0.45^{\mathrm{de}}$ & $47.76 \pm 2.34^{\mathrm{de}}$ \\
\hline & P0 X C1 & $56.39 \pm 0.31^{\mathrm{de}}$ & $42.50 \pm 0.83^{\mathrm{e}}$ & $45.44 \pm 0.66^{\mathrm{bc}}$ & $48.11 \pm 0.17^{\mathrm{de}}$ \\
\hline & P0 X C2 & $65.32 \pm 0.31^{b c}$ & $48.06 \pm 2.17^{\mathrm{cde}}$ & $42.58 \pm 2.31^{\mathrm{bcd}}$ & $51.99 \pm 1.60^{\mathrm{cd}}$ \\
\hline & P0 X C3 & $60.12 \pm 0.62^{\text {cde }}$ & $45.44 \pm 0.66^{\mathrm{de}}$ & $42.03 \pm 1.72^{\mathrm{cd}}$ & $49.20 \pm 0.15^{\text {de }}$ \\
\hline & P1 X C0 & $48.06 \pm 0.18^{f}$ & $35.96 \pm 1.85^{\mathrm{f}}$ & $35.92 \pm 1.14^{\mathrm{bc}}$ & $39.98 \pm 0.76^{\mathrm{f}}$ \\
\hline & P1 X C1 & $55.48 \pm 0.14^{\mathrm{de}}$ & $48.66 \pm 0.59^{\mathrm{cd}}$ & $44.65 \pm 1.24^{b c}$ & $49.59 \pm 0.66^{\text {cde }}$ \\
\hline & P1 X C2 & $54.13 \pm 1.28^{\mathrm{e}}$ & $44.21 \pm 2.27^{\mathrm{de}}$ & $41.43 \pm 0.14^{\mathrm{cd}}$ & $46.59 \pm 1.23^{\mathrm{e}}$ \\
\hline & P1 X C3 & $68.77 \pm 0.04^{\mathrm{ab}}$ & $55.40 \pm 1.04^{\mathrm{b}}$ & $47.74 \pm 0.69^{\mathrm{ab}}$ & $57.31 \pm 0.57^{\mathrm{b}}$ \\
\hline & $\mathrm{P} 2 \mathrm{X} \mathrm{C0}$ & $57.19 \pm 1.72^{\mathrm{de}}$ & $41.95 \pm 3.92^{\mathrm{e}}$ & $36.00 \pm 4.34^{\mathrm{e}}$ & $45.04 \pm 3.33^{\mathrm{e}}$ \\
\hline & P2 X C1 & $73.66 \pm 2.10^{\mathrm{a}}$ & $61.35 \pm 1.38^{\mathrm{a}}$ & $51.47 \pm 1.66^{\mathrm{a}}$ & $62.16 \pm 0.80^{\mathrm{a}}$ \\
\hline & $\mathrm{P} 2 \mathrm{X} \mathrm{C} 2$ & $64.33 \pm 2.75^{\mathrm{bc}}$ & $53.34 \pm 0.69^{\mathrm{bc}}$ & $44.93 \pm 0.04^{\mathrm{bc}}$ & $54.20 \pm 1.15^{\mathrm{bc}}$ \\
\hline & P2 X C3 & $\begin{array}{c}61.75 \pm 3.06^{\mathrm{cd}} \\
* *\end{array}$ & $\begin{array}{c}48.06 \pm 2.38^{\mathrm{cde}} \\
* *\end{array}$ & $\begin{array}{c}46.24 \pm 0.28^{\mathrm{bc}} \\
*\end{array}$ & $\begin{array}{c}52.02 \pm 1.72^{\mathrm{cd}} \\
* *\end{array}$ \\
\hline
\end{tabular}

a, b, c, d, e and f means with different superscripts within the same column are significantly different. $*=(\mathrm{P}<0.05)$ and $* *=(\mathrm{P}<0.01)$.

Egg weight (EW).

The results obtained in table (6) showed highly significant effect on average EW of laying hens at the period from 42-50 weeks of bird's age only which may be due to feeding diets with probiotic levels supplementation. The highest EW values were observed in hens fed diets supplemented with probiotic at a level of $0.5 \mathrm{~g} / \mathrm{Kg}$ diet when compared with other treatment and control group.

Table 6. Least square means and standard error $\left(\mathrm{X}^{-} \pm\right.$S.E. $)$for egg weight of birds of different experimental groups as affected by dietary supplementation.

\begin{tabular}{|c|c|c|c|c|c|}
\hline \multicolumn{2}{|c|}{ Variables } & \multicolumn{4}{|c|}{ Egg weight (g) at weeks } \\
\hline Treatments & $\begin{array}{c}\text { Levels } \\
\text { (g/kg diet) }\end{array}$ & $26-34$ & $34-42$ & $42-50$ & $\begin{array}{c}\text { Average } \\
(26-50)\end{array}$ \\
\hline \multirow{4}{*}{$\begin{array}{l}\text { Probiotic } \\
\text { (P) }\end{array}$} & $\mathrm{P} 0=$ control & $47.61 \pm 0.27$ & $49.75 \pm 0.21$ & $50.31 \pm 0.15^{\mathrm{a}}$ & $49.22 \pm 0.18$ \\
\hline & $\mathrm{P} 1=0.5$ & $48.03 \pm 0.31$ & $50.17 \pm 0.29$ & $50.56 \pm 0.16^{\mathrm{a}}$ & $49.59 \pm 0.23$ \\
\hline & $\mathrm{P} 2=1.0$ & $47.64 \pm 0.34$ & $49.84 \pm 0.23$ & $49.9 \pm 0.09^{b}$ & $49.13 \pm 0.18$ \\
\hline & & NS & NS & $* *$ & NS \\
\hline \multirow{5}{*}{$\begin{array}{l}\text { Chicory } \\
\text { (C) }\end{array}$} & $\mathrm{C} 0=$ control & $47.90 \pm 0.44^{\mathrm{ab}}$ & $50.31 \pm 0.27$ & $50.22 \pm 0.17 \mathrm{ab}$ & $49.47 \pm 0.26$ \\
\hline & $\mathrm{C} 1=5$ & $47.44 \pm 0.22^{\mathrm{b}}$ & $49.87 \pm 0.24$ & $50.52 \pm 0.15^{\mathrm{a}}$ & $49.27 \pm 0.13$ \\
\hline & $\mathrm{C} 2=10$ & $48.29 \pm 0.27^{\mathrm{a}}$ & $49.65 \pm 0.25$ & $50.17 \pm 0.18^{b}$ & $49.37 \pm 0.22$ \\
\hline & $\mathrm{C} 3=20$ & $47.41 \pm 0.46^{b}$ & $49.85 \pm 0.38$ & $50.14 \pm 0.1^{\mathrm{b}}$ & $49.13 \pm 0.29$ \\
\hline & & $*$ & NS & $*$ & NS \\
\hline \multirow{13}{*}{$\begin{array}{l}\text { Interactions } \\
(\mathrm{P} \times \mathrm{C})\end{array}$} & P0 X C0 & $46.71 \pm 0.24^{\mathrm{cd}}$ & $49.19 \pm 0.36$ & $49.57 \pm 0.17^{\mathrm{e}}$ & $48.49 \pm 0.26^{\mathrm{c}}$ \\
\hline & P0 X C1 & $48.87 \pm 0.13^{\mathrm{a}}$ & $49.90 \pm 0.33$ & $50.76 \pm 0.02^{\mathrm{ab}}$ & $49.84 \pm 0.15^{\mathrm{ab}}$ \\
\hline & $\mathrm{P} 0 \mathrm{X} \mathrm{C} 2$ & $47.71 \pm 0.38^{a b c}$ & $49.60 \pm 0.61$ & $50.59 \pm 0.03^{a b c}$ & $49.30 \pm 0.33^{a b c}$ \\
\hline & P0 X C3 & $47.14 \pm 0.08^{c}$ & $50.30 \pm 0.10$ & $50.34 \pm 0.08^{\mathrm{bcd}}$ & $49.26 \pm 0.08^{a b c}$ \\
\hline & P1 X C0 & $48.49 \pm 0.44^{\mathrm{ab}}$ & $50.98 \pm 0.46$ & $50.82 \pm 0.27^{\mathrm{ab}}$ & $50.10 \pm 0.39^{a}$ \\
\hline & P1 X C1 & $47.58 \pm 0.34^{\mathrm{abc}}$ & $50.14 \pm 0.24$ & $50.93 \pm 0.41^{\mathrm{a}}$ & $49.55 \pm 0.33^{\mathrm{ab}}$ \\
\hline & P1 X C2 & $48.62 \pm 0.79^{a b}$ & $49.98 \pm 0.88$ & $50.06 \pm 0.18^{\text {cde }}$ & $49.55 \pm 0.62^{\mathrm{ab}}$ \\
\hline & P1 X C3 & $47.41 \pm 0.78^{b c}$ & $49.59 \pm 0.49$ & $50.42 \pm 0.09$ abcd & $49.14 \pm 0.45^{\mathrm{abc}}$ \\
\hline & P2 X C0 & $48.49 \pm 0.04^{\mathrm{ab}}$ & $50.75 \pm 0.45$ & $50.25 \pm 0.17^{\mathrm{bcd}}$ & $49.83 \pm 0.20^{\mathrm{ab}}$ \\
\hline & P2 X C1 & $45.85 \pm 0.09^{\mathrm{d}}$ & $49.57 \pm 0.17$ & $49.86 \pm 0.05^{\mathrm{de}}$ & $48.43 \pm 0.02^{c}$ \\
\hline & $\mathrm{P} 2 \mathrm{X}$ C2 & $48.54 \pm 0.09^{a b}$ & $49.38 \pm 0.15$ & $49.85 \pm 0.19^{\mathrm{de}}$ & $49.26 \pm 0.09 a b c$ \\
\hline & P2 X C3 & $46.71 \pm 0.24^{\mathrm{cd}}$ & $49.66 \pm 0.52$ & $49.65 \pm 0.13^{\mathrm{e}}$ & $49.00 \pm 0.32^{\mathrm{bc}}$ \\
\hline & & $* *$ & NS & $* *$ & $* *$ \\
\hline
\end{tabular}

a, b, c, d and e means with different superscripts within the same column are significantly different. $*=(\mathrm{P}<0.05)$ and $* *=(\mathrm{P}<0.01)$. 
The results obtained may be due to increasing enzymatic activated in the gut, resulting in improving nutrient utilization (Khan et al., 2011). The results obtained go in harmony with those stated by Ramasamy et al. (2009) who reported that the inclusion of Lactobacillus in laying hens' diet (between 20 and 44 weeks of age) significantly increased EW. Also, Beshara and Ayman (2019) noted that the dietary supplementation of probiotics with $0.5 \mathrm{~g}$ probiotic / $\mathrm{kg}$ diet on $\mathrm{EW}$ was increased significantly $(\mathrm{P} \leq 0.05)$ due to dietary treatment as compared to the control in laying Sinai hens.

Significant variations $(\mathrm{P}<0.05)$ on $\mathrm{EW}$ were found in dietary chicory supplementations groups at the periods from (26-34) and (42-50) and were highly significant effected $(\mathrm{P}<0.01)$ at the same periods in addition to all periods due to the interaction between chicory and probiotic. The higher EW were found in control group and in interactions between (P1 X C0) and (P0 X C1).These results are in close agreement with those obtained by AL Amery (2009) they declared that using chicory powder and probiotics significant improved in EW of Isa Brown hens.

\section{Egg mass}

The result obtained in table (7) revealed that hens fed diet supplement with different levels of probiotic showed the highest significant $(\mathrm{P}<0.01)$ effect on egg mass at all periods of estimation except at (42-50) weeks. The highest egg mass values were observed in hens fed diets supplemented with probiotic at a level of $1.0 \mathrm{~g} / \mathrm{Kg}$ diet when compared with others treatment applied. Abdo et al., (2001) stated that dietary supplementation of probiotic ( $1 \mathrm{~g} / \mathrm{kg}$ diet) had significantly increase in egg mass of local strains (Fayoumi and dandarawi). Egg mass was high significantly $(\mathrm{P}<0.01) \quad$ increased by dietary supplementation of chicory and the most interactions between chicory and probiotic at all experimental periods. Hens fed diet supplemented with chicory at a level of $5 \mathrm{~g} / \mathrm{kg}$ diet showed the highest averages of egg mass (26.22) and the interaction between P2 X C1 $(33.78 \mathrm{~g} / \mathrm{hen} /$ day $)$ compared with others treatments applied. The positive effect of chicory supplementation on egg mass could be attributed to the effects of prebiotics on gut microflora (Ghareeb et al., 2008).

Table 7. Least square means and standard error $\left(\mathrm{X}^{-} \pm\right.$S.E.) for egg mass of birds of different experimental groups as affected by dietary supplementation.

\begin{tabular}{|c|c|c|c|c|c|}
\hline \multicolumn{2}{|c|}{ Variables } & \multicolumn{4}{|c|}{ Egg mass (g/hen/day) at weeks } \\
\hline Treatments & $\begin{array}{c}\text { Levels } \\
\text { (g/kg diet) }\end{array}$ & 26-34 & 34-42 & $42-50$ & $\begin{array}{c}\text { Average } \\
(26-50)\end{array}$ \\
\hline \multirow{3}{*}{$\begin{array}{l}\text { Probiotic } \\
\text { (P) }\end{array}$} & $\mathrm{P} 0=$ control & $28.18 \pm 0.8^{b}$ & $23.05 \pm 0.52^{b}$ & $21.29 \pm 0.51$ & $24.26 \pm 0.43^{b}$ \\
\hline & $\mathrm{P} 1=0.5$ & $27.16 \pm 1.06^{\mathrm{b}}$ & $23.08 \pm 1.08^{\mathrm{b}}$ & $21.45 \pm 0.7$ & $23.97 \pm 0.92^{b}$ \\
\hline & $\mathrm{P} 2=1.0$ & $\begin{array}{c}30.55 \pm 0.86^{\mathrm{a}} \\
* *\end{array}$ & $\begin{array}{c}25.49 \pm 1.17^{\mathrm{a}} \\
* *\end{array}$ & $\begin{array}{c}22.28 \pm 0.97 \\
\text { NS }\end{array}$ & $\begin{array}{c}26.19 \pm 0.95^{\mathrm{a}} \\
* *\end{array}$ \\
\hline \multirow{4}{*}{$\begin{array}{l}\text { Chicory } \\
\text { (C) }\end{array}$} & $\mathrm{C} 0=$ control & $25.56 \pm 1.26^{\mathrm{b}}$ & $21.3 \pm 1.45^{b}$ & $18.58 \pm 1.21^{\mathrm{c}}$ & $21.89 \pm 1.19^{b}$ \\
\hline & $\mathrm{C} 1=5$ & $29.25 \pm 0.68^{\mathrm{a}}$ & $25.34 \pm 0.68^{\mathrm{a}}$ & $23.83 \pm 0.43^{\mathrm{a}}$ & $26.22 \pm 0.49^{a}$ \\
\hline & $\mathrm{C} 2=10$ & $29.58 \pm 0.59^{\mathrm{a}}$ & $24.11 \pm 1.17^{\mathrm{a}}$ & $21.56 \pm 0.90^{\mathrm{b}}$ & $25.15 \pm 0.86^{\mathrm{a}}$ \\
\hline & $\mathrm{C} 3=20$ & $\begin{array}{c}30.14 \pm 1.23^{\mathrm{a}} \\
* *\end{array}$ & $\begin{array}{c}24.74 \pm 1.13^{\mathrm{a}} \\
* *\end{array}$ & $\begin{array}{c}22.73 \pm 0.62^{\mathrm{ab}} \\
* *\end{array}$ & $\begin{array}{c}25.96 \pm 0.98^{\mathrm{a}} \\
* *\end{array}$ \\
\hline \multirow{12}{*}{$\begin{array}{l}\text { Interactions } \\
\quad(\mathrm{P} \times \mathrm{C})\end{array}$} & P0 X C0 & $25.64 \pm 2.4$ ef & $24.26 \pm 1.02^{\mathrm{bcd}}$ & $19.40 \pm 0.29$ & $23.17 \pm 1.26^{\mathrm{de}}$ \\
\hline & P0 X C1 & $27.56 \pm 0.08 \mathrm{de}$ & $21.20 \pm 0.28^{\mathrm{de}}$ & $23.07 \pm 0.33$ & $23.98 \pm 0.02 \mathrm{de}$ \\
\hline & P0 X C2 & $31.17 \pm 0.40^{\mathrm{abc}}$ & $23.86 \pm 1.37^{\mathrm{cd}}$ & $21.54 \pm 1.16$ & $25.64 \pm 0.96^{\mathrm{bcd}}$ \\
\hline & P0 X C3 & $28.34 \pm 0.34^{\text {cde }}$ & $22.86 \pm 0.37^{\mathrm{cd}}$ & $21.15 \pm 0.84$ & $24.23 \pm 0.04$ cde \\
\hline & $\mathrm{P} 1 \mathrm{X} \mathrm{C0}$ & $23.31 \pm 0.30^{\mathrm{f}}$ & $18.33 \pm 0.92^{\mathrm{e}}$ & $18.25 \pm 0.49$ & $20.03 \pm 0.31^{\mathrm{f}}$ \\
\hline & P1 X C1 & $26.40 \pm 0.26^{\mathrm{def}}$ & $24.40 \pm 0.41^{\mathrm{bcd}}$ & $22.75 \pm 0.82$ & $24.58 \pm 0.49^{\mathrm{cde}}$ \\
\hline & P1 X C2 & $26.34 \pm 1.05^{\mathrm{def}}$ & $22.14 \pm 1.52^{\mathrm{d}}$ & $20.74 \pm 0.15$ & $23.10 \pm 0.90$ \\
\hline & P1 X C3 & $32.60 \pm 0.55^{\mathrm{ab}}$ & $27.46 \pm 0.25^{\mathrm{ab}}$ & $24.07 \pm 0.31$ & $28.15 \pm 0.03^{a b}$ \\
\hline & $\mathrm{P} 2 \mathrm{X} \mathrm{C0}$ & $27.73 \pm 0.82^{\mathrm{de}}$ & $21.33 \pm 2.18^{\mathrm{de}}$ & $18.10 \pm 2.24$ & $22.46 \pm 1.75^{f}$ \\
\hline & P2 X C1 & $33.78 \pm 1.03^{\mathrm{a}}$ & $30.42 \pm 0.79^{\mathrm{a}}$ & $25.66 \pm 0.85$ & $30.10 \pm 0.38^{a}$ \\
\hline & $\mathrm{P} 2 \mathrm{X} \mathrm{C} 2$ & $31.22 \pm 1.29^{\mathrm{abc}}$ & $26.34 \pm 0.42^{b c}$ & $22.39 \pm 0.09$ & $26.70 \pm 0.61^{\mathrm{bc}}$ \\
\hline & P2 X C3 & $\begin{array}{c}29.46 \pm 1.64 \text { bcd } \\
* *\end{array}$ & $\begin{array}{c}23.89 \pm 1.43^{\mathrm{cd}} \\
* *\end{array}$ & $\begin{array}{c}22.96 \pm 0.08 \\
* *\end{array}$ & $\begin{array}{c}25.50 \pm 1.01^{\mathrm{cd}} \\
* *\end{array}$ \\
\hline
\end{tabular}

$\mathrm{a}, \mathrm{b}, \mathrm{c}, \mathrm{d}$, e and f means with different superscripts within the same column are significantly different. $* *=(\mathrm{P}<0.01)$.

\section{Humoral immune response: \\ Antibody titers of Newcastle (ND) and Influenza (H9N2).}

Data presented in table (8) showed that hens fed on diet supplemented with probiotic had significantly increased the immune response towards antibody titer against Newcastle disease virus (NDV) and avian influenza (H9N2) at the end of experimental period. The higher antibody titer of H9N2 and NDV were observed in hens fed diets supplemented with probiotic at a level of 1.0 and $0.5 \mathrm{~g} / \mathrm{kg}$ diet $(7.00$ and 6.59) and (5.92 and 5.00), respectively when 
compared with control group. The positive effect of feeding diet containing probiotic on the immune response indicates the enhancement of the formulating bacteria on an acquired immune response exerted by $\mathrm{T}$ and $\mathrm{B}$ lymphocytes. The direct effect might be related to stimulate the lymphatic tissue (Kabir et al., 2004). These results are in agreement with those reported by Rowghani et al., (2007) and Alkhalf $\boldsymbol{e t}$ al., (2010b) they stated that broiler chickens fed diet supplemented with probiotic had a significant increase in the Newcastle antibody titers compared with those of control group. The results obtained disagree with those reported by Fathi et al., (2018) and Shehata $\boldsymbol{e t}$ al., (2019) they stated that no significant differences by addition of bacteria (B. subtilis or P. acidilactici) alone or combined supplementation in broiler diet on of Newcastle and Influenza values among the treated groups compared to the control groups.

Insignificant variations in average antibody titer against Newcastle disease virus and avian influenza were found in hens of different experimental groups due to dietary chicory level supplementation and the interactions between chicory and probiotic at all periods of estimation.

Table 8. Least square means and standard error $\left(\mathrm{X}^{-} \pm\right.$S.E. $)$for the antibody titer of Newcastle disease virus (NDV) and A vain influenza (H9N2) of birds of different experimental groups as affected by dietary supplementation at the end of experimental period.

\begin{tabular}{|c|c|c|c|}
\hline \multicolumn{2}{|c|}{ Variables } & \multirow[b]{2}{*}{ H9N2 } & \multirow[b]{2}{*}{ NDV } \\
\hline Treatments & $\begin{array}{c}\text { Levels } \\
\text { (g/kg diet) }\end{array}$ & & \\
\hline \multirow{3}{*}{$\begin{array}{l}\text { Probiotic } \\
\text { (P) }\end{array}$} & $\mathrm{P} 0=$ control & $5.84 \pm 0.33^{b}$ & $4.42 \pm 0.42^{b}$ \\
\hline & $\mathrm{P} 1=0.5$ & $6.59 \pm 0.23^{\mathrm{a}}$ & $5.00 \pm 0.31^{\mathrm{ab}}$ \\
\hline & $\mathrm{P} 2=1.0$ & $\begin{array}{c}7.00 \pm 0.18^{\mathrm{a}} \\
*\end{array}$ & $\begin{array}{c}5.92 \pm 0.32^{\mathrm{a}} \\
*\end{array}$ \\
\hline \multirow{4}{*}{$\begin{array}{l}\text { Chicory } \\
\text { (C) }\end{array}$} & $\mathrm{C} 0=$ control & $6.12 \pm 0.35$ & $4.56 \pm 0.48$ \\
\hline & $\mathrm{C} 1=5$ & $6.12 \pm 0.32$ & $4.78 \pm 0.46$ \\
\hline & $\mathrm{C} 2=10$ & $6.67 \pm 0.28$ & $5.34 \pm 0.41$ \\
\hline & $\mathrm{C} 3=20$ & $7.00 \pm 0.26$ & $5.78 \pm 0.28$ \\
\hline \multirow{14}{*}{$\begin{array}{l}\text { Interactions } \\
\quad(\mathrm{P} \times \mathrm{C})\end{array}$} & & NS & NS \\
\hline & P0 X C0 & $5.34 \pm 0.89$ & $3.34 \pm 0.34$ \\
\hline & P0 X C1 & $5.34 \pm 0.34$ & $4.34 \pm 0.89$ \\
\hline & P0 X C2 & $6.00 \pm 0.58$ & $5.00 \pm 1.00$ \\
\hline & P0 X C3 & $6.67 \pm 0.67$ & $5.00 \pm 1.00$ \\
\hline & P1 X C0 & $6.34 \pm 0.34$ & $4.67 \pm 0.67$ \\
\hline & P1 X C1 & $6.34 \pm 0.67$ & $4.67 \pm 0.89$ \\
\hline & P1 X C2 & $6.67 \pm 0.34$ & $5.00 \pm 0.58$ \\
\hline & P1 X C3 & $7.00 \pm 0.58$ & $5.67 \pm 0.34$ \\
\hline & $\mathrm{P} 2 \mathrm{X} \mathrm{C0}$ & $6.67 \pm 0.34$ & $5.67 \pm 0.67$ \\
\hline & $\mathrm{P} 2 \mathrm{X} \mathrm{C} 1$ & $6.67 \pm 0.34$ & $5.34 \pm 0.89$ \\
\hline & $\mathrm{P} 2 \mathrm{X} \mathrm{C} 2$ & $7.34 \pm 0.34$ & $6.00 \pm 0.58$ \\
\hline & $\mathrm{P} 2 \mathrm{X} \mathrm{C} 3$ & $7.34 \pm 0.34$ & $6.67 \pm 0.34$ \\
\hline & & NS & NS \\
\hline
\end{tabular}

$\mathrm{a}$ and $\mathrm{b}$ means with different superscripts within the same column are significantly different. $*=(\mathrm{P}<0.05)$.

\section{Economic efficiency:}

Results presented in table (9) showed the relative economical efficiency values ranged from 85.90 to $129.20,189.29$ to 281.39 and 15.10 to $270.14 \%$ for diets supplemented with different levels of probiotic, chicory and their interactions, respectively. Moreover, the highest values of relative economical efficiency $129.20,281.39$ and $270.14 \%$ listed for diets containing $1.0 \mathrm{~g}$ probiotic, $5 \mathrm{~g}$ chicory $/ \mathrm{Kg}$ diet and their interactions between $\mathrm{P} 2 \mathrm{X} \mathrm{C1}$, receptively. This improvement could be due to improving egg weight, egg mass, and feed conversion ratio. These results were agreed with those stated by Riad et al., (2010) who indicated that both net revenue and economical efficiency increased in probiotic additives treatments than control ones. Also, Mahmoud (2017) observed that high economical return and relative economic efficiency (REE) were found in $1 \%$ dried chicory leaves while; the lowest values were occurred with 2 $\%$ diet.

In conclusion, the results of this study indicate that feeding Inshas laying hens on diets containing $1.0 \mathrm{~g}$ probiotic or $5 \mathrm{~g}$ chicory $/ \mathrm{Kg}$ diet and their interaction between, P2XC1 (1.0 g probiotic x $5 \mathrm{~g}$ chicory $/ \mathrm{Kg}$ diet) improved the productive performance and economical efficiency of Inshas laying hens. 
Table 9. Economical efficiency of different experimental groups as affected by studied factors at the end of the experiment.

\begin{tabular}{|c|c|c|c|c|c|c|c|c|c|c|}
\hline \multicolumn{2}{|l|}{ Variables } & \multicolumn{9}{|c|}{ Economical efficiency } \\
\hline Treatments & $\begin{array}{l}\text { Levels } \\
\text { (g/kg diet) }\end{array}$ & $\begin{array}{l}\text { Total } \\
\text { number } \\
\text { of } \\
\text { eggs/hen }\end{array}$ & $\begin{array}{l}\text { Price/ } \\
\text { egg } \\
(\mathrm{LE})^{1}\end{array}$ & $\begin{array}{l}\text { Price of total } \\
\text { eggs } \\
\text { production/hen } \\
\text { (LE) }\end{array}$ & $\begin{array}{l}\text { Total } \\
\text { feed } \\
\text { intake/ } \\
\text { hen }(\mathrm{Kg})\end{array}$ & $\begin{array}{l}\text { Price/kg } \\
\text { feed } \\
\text { (LE) }\end{array}$ & $\begin{array}{l}\text { Total } \\
\text { feed } \\
\text { cost/hen } \\
\text { (LE) }\end{array}$ & $\begin{array}{l}\text { Net } \\
\text { revenue/hen } \\
(\mathrm{LE})^{2}\end{array}$ & $\begin{array}{l}\text { Economical } \\
\text { efficiency } \\
(\mathrm{EEf})^{3}\end{array}$ & $\begin{array}{l}\text { Relative } \\
\text { economical } \\
\text { efficiency } \\
(\%)^{4}\end{array}$ \\
\hline \multirow{4}{*}{$\begin{array}{l}\text { Probiotic } \\
\text { (P) }\end{array}$} & $\mathrm{P} 0=$ control & 82.76 & 1.4 & 115.86 & 20.23 & 4.54 & 91.86 & 24.00 & 0.26 & 100.00 \\
\hline & $\mathrm{P} 1=0.5$ & 81.26 & 1.4 & 113.77 & 20.04 & 4.64 & 92.92 & 20.85 & 0.22 & 85.90 \\
\hline & $\mathrm{P} 2=1.0$ & 89.63 & 1.4 & 125.48 & 20.22 & 4.64 & 93.82 & 31.66 & 0.34 & 129.20 \\
\hline & $\mathrm{C} 0=$ control & 74.36 & 1.4 & 104.10 & 20.29 & 4.50 & 91.29 & 12.80 & 0.14 & 100.00 \\
\hline \multirow{7}{*}{$\begin{array}{l}\text { Chicory } \\
\text { (C) }\end{array}$} & $\mathrm{C} 1=5$ & 89.53 & 1.4 & 125.34 & 20.21 & 4.45 & 89.87 & 35.47 & 0.39 & 281.39 \\
\hline & $\mathrm{C} 2=10$ & 85.56 & 1.4 & 119.79 & 19.97 & 4.66 & 93.04 & 26.75 & 0.29 & 204.99 \\
\hline & $\mathrm{C} 3=20$ & 88.77 & 1.4 & 124.28 & 20.19 & 4.82 & 97.24 & 27.04 & 0.28 & 198.24 \\
\hline & $\mathrm{PO} \times \mathrm{CO}$ & 80.24 & 1.4 & 112.33 & 20.40 & 4.4 & 89.75 & 22.59 & 0.25 & 100.00 \\
\hline & $\mathrm{P} 0 \mathrm{X} \mathrm{C} 1$ & 80.82 & 1.4 & 113.15 & 20.27 & 4.48 & 90.82 & 22.33 & 0.25 & 97.72 \\
\hline & $\mathrm{P} 0 \times \mathrm{C} 2$ & 87.34 & 1.4 & 122.28 & 20.11 & 4.56 & 91.71 & 30.57 & 0.33 & 132.47 \\
\hline & $\mathrm{P} 0 \mathrm{X} \mathrm{C} 3$ & 82.66 & 1.4 & 115.72 & 20.15 & 4.72 & 95.13 & 20.59 & 0.22 & 85.99 \\
\hline \multirow{8}{*}{$\begin{array}{l}\text { Interactions } \\
\text { (P X C) }\end{array}$} & $\mathrm{P} 1 \mathrm{X} \mathrm{C} 0$ & 67.17 & 1.4 & 94.03 & 20.13 & 4.5 & 90.59 & 3.44 & 0.04 & 15.10 \\
\hline & P1 X C1 & 83.31 & 1.4 & 116.64 & 20.02 & 4.58 & 91.69 & 24.94 & 0.27 & 108.09 \\
\hline & $\mathrm{P} 1 \mathrm{X} \mathrm{C} 2$ & 78.27 & 1.4 & 109.58 & 19.84 & 4.66 & 92.47 & 17.11 & 0.19 & 73.55 \\
\hline & $\mathrm{P} 1 \mathrm{X} \mathrm{C} 3$ & 96.28 & 1.4 & 134.79 & 20.15 & 4.81 & 96.90 & 37.89 & 0.39 & 155.36 \\
\hline & $\mathrm{P} 2 \mathrm{X} \mathrm{C0}$ & 75.67 & 1.4 & 105.93 & 20.34 & 4.6 & 93.56 & 12.38 & 0.13 & 52.58 \\
\hline & $\mathrm{P} 2 \mathrm{X} \mathrm{C}_{1}$ & 104.43 & 1.4 & 146.20 & 20.33 & 4.28 & 87.03 & 59.17 & 0.68 & 270.14 \\
\hline & $\mathrm{P} 2 \mathrm{X} \mathrm{C}^{2}$ & 91.06 & 1.4 & 127.48 & 19.94 & 4.76 & 94.91 & 32.56 & 0.34 & 136.33 \\
\hline & $\mathrm{P} 2 \mathrm{X} \mathrm{C} 3$ & 87.39 & 1.4 & 122.35 & 20.26 & 4.92 & 99.69 & 22.66 & 0.23 & 90.32 \\
\hline
\end{tabular}

1- LE= 1 Egyptian pound.

2- Net revenue/hen (LE.) = price of total egg production/hen $(\mathrm{LE})-$ total feed cost/ hen

3- Economical efficiency $=$ net revenue/ price of feed intake.

4- Relative economical efficiency $=$ assuming that the relative economical efficiency (EEf) of the control $=100$.

\section{References}

Abdo, Z. M. A.Madein, A. H., Awed-Allah, M. A. and Soliman, A. Z. M. (2001). Laying performance of fayoumi and dandarawi hens as affected by addition of some probiotic preparations . Mansoura Journal of Agricultural Science /Vol. 26, no. 10.

Alkhalf, A., Alhaj, M. and Al-Homidan, I. (2010a). Influence of probiotic supplementation on blood parameters and growth performance in broiler chickens. Saudi journal of biological sciences, 17(3), 219-225.

Alkhalf, A., Alhaj, M. and Al-Homidan, I. (2010b). Influence of probiotic supplementation on immune response of broiler chicks. Egyptian Poultry Science, 30(1), 271-80.

AL Amery, M. M. A. (2009). Effect usage synbiotic (cichory powder \&s. cerevisiaesome) traits eggs quality in advance ages. Kufa Journal for Agricultural Science, 1(2), 93-100.

Association of Official Analytical Chemists, AOAC. (1990). Official Methods of Analysis, 15 th Ed, published by the AOAC.Washington, DC. USA.

Awad, W. A., Ghareeb, K., Abdel-Raheem, S. and Böhm, J. (2009). Effects of dietary inclusion of probiotic and synbiotic on growth performance, organ weights, and intestinal histomorphology of broiler chickens. Poultry Science 88, 49-55.

Bais, H. P. and Ravishankar, G. A. (2001). Cichorium intybus L. Cultivation, processing, utility, value addition and biotechnology, with an emphasis
Beshara, M. M., and Ayman, A. (2019). Effect of dietary probiotic supplementation during rearing period on subsequent laying performance of local laying hens. Egyptian Poultry Science Journal, 39(3), 625-637.

Chen, Y. C., Nakthong, C., and Chen, T. C. (2005). Improvement of laying hen performance by dietary prebiotic chicory oligofructose and inulin. International Journal of Poultry Science, 4(2), 103-108.

Duncan, D. B. (1955). Multiple range and F. test. Biometrics 11:1-42.

Edens, F.W. (2003). An alternative for antibiotic use in poultry probiotics. Brazilian Journal of Poultry Science 5, 75-97.

EMA., (2012). Community herbal monograph on Cichorium intybus L., radix. EMA/HMPC/121816/2010, May 22, 2012, European Medicines Agency (EMA) and Committee on Herbal Medicinal Products (HMPC), London, UK

Fathi, M. A., Namra, M. M. M., Ragab, M. S. and Aly, M. M. M. (2018). Effect of dietary supplementation of bacteria as growth promoters on performance of broiler chickens. Egyptian Poultry Science Journal, Vol. 38 Issue 2, p391408.

Ghareeb, K., Awad, W. A., Nitsch, S., AbdelRaheem, S. and Bohm, J. (2008). Fear behavior, ease of capture and performance traits of growing meat type chickens. Int J Poult Sci. 7:1185-1189

Grashorn, M.A. (2010). Use of phytobiotics in broiler nutrition - an alternative to in feed antibiotics?J. Anim. Feed Sci., 19: 338-347. 
Hatab, M. H., Elsayed, M. A. and Ibrahim, N. S. (2016). Effect of some biological supplementation on productive performance, physiological and immunological response of layer chicks. Journal of Radiation Research and Applied Sciences, 9(2), 185-192.

Kabir, S.M.L., Rahman, M. M., Rahman, M.B., and Ahmed, S. U. (2004). The dynamic of probiotics on growth performance and immune reponse in broilers. Poult. Sc.; 3(5): 361-364.

Khan, S.H., Atif, M., Mukhtar, N., Rehman, A. and Fareed, G. (2011) Effects of supplementation of multi-enzyme and multi-species probiotic on production performance, egg quality, cholesterol level and immune system in laying hens. J. Appl. Anim. Res., 39(4): 386-398.

Lalev, M., Oblakova, M., Hristakieva, P., Minceva, N., and Ivaniva, I. (2011). Investigation of dietary probiotic effects on productive traits in broiler breeders. Archiva Zootechnica, 14(2), 57-65.

Lin, Z., Zhang, B., Liu, X., Jin, R., and Zhu, W. (2014). Effects of chicory inulin on serum metabolites of uric acid, lipids, glucose, and abdominal fat deposition in quails induced by purine-rich diets. Journal of medicinal food, 17(11), 1214-1221.

Mahmoud, Y. M. M. (2017) Effect of Dietary Supplementation of Dried C.hicory (Cichorium intybus L.)Leaves in Diets on Growth Performance of Rabbits. J.Animal and Poultry Prod., Mansoura Univ., Vol.8(4): $69-77$.

Mansoub, N. H. (2011). Evaluation of herbal plant on different parameters of laying hens. Ann Biol Res, 2(5), 510-515.

Mikulski, D. 1., Jankowski, J., Naczmanski, J., Mikulska, M. and Demey, V. (2012). Effects of dietary probiotic (Pediococcus acidilactici) supplementation on performance, nutrient digestibility, egg traits, egg yolk cholesterol, and fatty acid profile in laying hens. Poultry science, 91(10), 2691-2700.

National Research Council, NRC. (1994). Nutrient Requirements of Poultry. 9 $^{\text {th }}$ Revised Edition, National Academy Press, Washington, D.C., USA.

Nobakht, A. (2015). Effects of Cichorium intybus L. on performance, egg traits, blood biochemical and cellular parameters of laying hens. Animal Production Research, Vol. 4, No. 3, 47-55.

OIE, (2008). Manual of Diagnostic Tests and Vaccines for Terrestrial Animals: Mammals, Birds and Bees, Biological Standards Commission, 6th ed. World Organization for Animal Health, Paris, pp. 576-589.

Perić, L., Milošević, N., Žikić, D., Bjedov, S., Cvetković, D., Markov, S. and Steiner, T.
(2010). Effects of probiotic and phytogenic products on performance, gut morphology and cecal microflora of broiler chickens. Archives Animal Breeding, 53(3), 350-359

Quarantelli A., Righi F, Agazzi A., Invernizzi G., Ferroni M. and Chevaux E. (2008). Effects of the administration of Pediococcus acidilactici to laying hens on productive performance. Vet. Res. Commun. 32: S, 359-361.

Ramasamy, K., Abdullah, N., Jalaludin, S., Wong M. and Ho, Y.W. (2009). Effects of Lactobacillus cultures on performance of laying hens, and total cholesterol, lipid and fatty acid composition of egg yolk. J. Sci. Food. Agric. 89(3), 482-486

Rehman, H.; Hellweg, P.; Taras, D. and Zentek, J., (2008): Effects of dietary inulin on the intestinal short-chain fatty acids and microbial ecology in broiler chickens as revealed by denaturing gradient gel electrophoresis. Poultry Science 87, 783-789.

Riad, S. A., Safaa, H. M. and Mohamed, F. R. (2010). Influence of probiotic, prebiotic and/or yeast supplementation in broiler diets on the productivity, immune response and slaughter traits.J. of Animal and Poultry Production, Vol. 1 (2): $45-60$

Rowghani, E., Arab M. and Akbarian, A. (2007): Effects of a Probiotic and Other Feed Additives on Performance and Immune Response of Broiler Chicks. International Journal of Poultry Science 6: 261-265.

SAS, (2004). SAS User's Guide: Statistics. Version 9.1. SAS Inst. Inc., Cary, NC., USA.

Shehata, A. A., Tarabees, R., Basiouni, S., ElSayed, M. S., Gaballah, A. and Krueger, M. (2019). Effect of a Potential Probiotic Candidate Enterococcus faecalis-1 on Growth Performance, Intestinal Microbiota, and Immune Response of Commercial Broiler Chickens. Probiotics and antimicrobial proteins, pp 1-10.

Taraz, Z., Shargh, M. S., Samadi, F., Ebrahimi, P. and Zerehdaran, S. (2015). Effect of Chicory plant (Cichorium intybus L.) extract on performance and blood parameters in broilers exposed to heat stress with emphasis on antibacterial properties. Poultry Science Journal, 3(2), 151-158.

VanWyk, B., Oudtshoorn, B. and Gericke, N. (1997). Medicinal Plants of South Africa. Briza Publications, Pretoria Pages: 234.

Windisch W., Schedle K., Plitzne,r C. and Kroismayr, A. (2008). Use of phytogenic products as feed additives for swine and poultry. J. Anim. Sci., 86: 140-148. 


\section{تأثير استخدام الفيتوجيتك والبروبيوتك للعليقه على الاداء الانتاجى والاستجابه المناعيه لاجاج أنشاص البياض.}

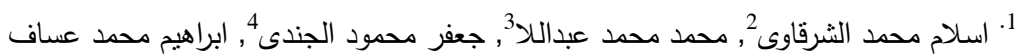

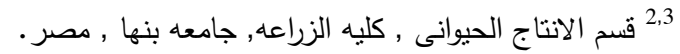

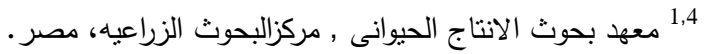

أجريت هذه الدراسـهـ بمزرعه محطه بحوث تربيه الدواجن بأنثــاص التابعه لمعهد بحوث الاتناج الحيوانى, مركز البحوث الزراعيه , مصـر خلال الفتره من سبتمبر 2017حتى مارس 2018 وتهدف الدراسـه الى تقييم تاثير اضـافه مستويات مختلفه من البروبيوتك ممنلك في بكتريا البيديوكوكس

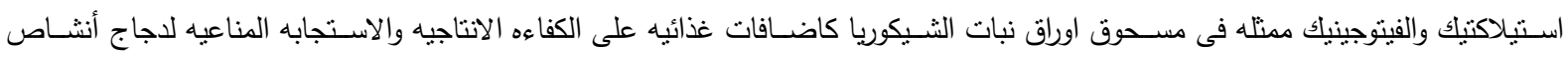
البياض كسلاله محليه لانتاج البيض. اسـتخدم فى هذه الدراســ 720 دجاجه بياضــه عمر 26 اسـبوع وزعت عثـوائيا الى 12 مجموعه تجريبيه (كل مجموعه بها 60 دجاجه ) وكانت

طيور المجاميع منمانله تقريبا فى وزن الجسم والانتاج اليومى من البيض, قسمت طيور كل مجموعه الى 3 مكررات بكل منها (20 دجاجه).

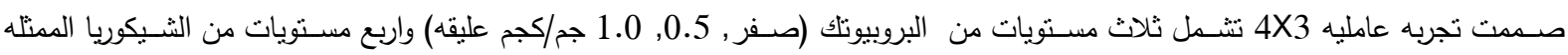
للفيتوجنيك (صفر , 5, 10, 20جم/كجم عليقه) والتداخلات بينهم واستمرت التجربه لمده 24 اسبوع. ويمكن تلخيص النتائج المتحصل عليها فيما يلى :

اظهرت الطيور المغذاه على مستويات مختلفه من البروبيوتك والثـيكوريا والتداخلات بينهم تاثيرا عالى المعنويه (عند مستوى 0.01 \% ) على كفاءه تحويل الغذاء وانتاج البيض وكتله البيضه فى معظم فترات ومتوسط الفتره الكليه للتجربه.

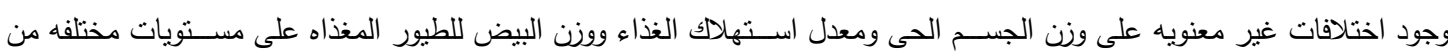
البروبيوتلك والثــيكوريا , فى حين ظهر تاثيرعالى المعنويه للتداخل بين مسـنتويات الثـيكوريا والبروبيوتلك على وزن الجسـم الحى ووزن البيض فقط.

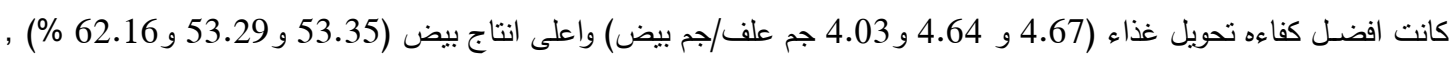

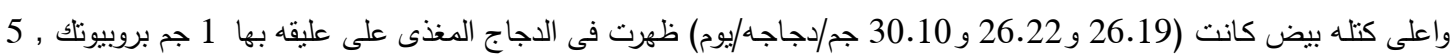
جم شيكوريا والتداخل بين نفس المستويين , على التوالى. اظهرت النتائج تحسـين معنوى (عند مسـتوى 0.05\%) على الاسـتجابه المناعيه تجاه الاجسـام المناعبه لفيرس النيوكاسـل والانفلونزا لمسنويات البروبيونك فقط. سجلت الطيورالمغذاه على عليقه بها 5جم شيكوريا, 10.1جم بروبيوتك والتداخل بينهما (0.5جم بروبيوتلك مع5جم شيكوريا) على الترتيب اعلى كفاءه اقتصادية 129.20, 281.39, 270.14, على الترتيب). وبصفه عامه بمكن ان نوصى باضافه البروبيوتلك بمعدل 1 جم والثيكوريا بمعدل 5 جم /كجم عليقه اوالتذاخل بين (1جم بروبيونك مع

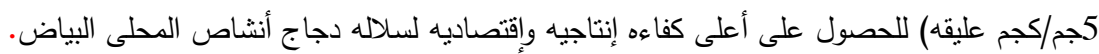

